\title{
Investigação científica da governança da educação: tendências empíricas e teóricas
}

\author{
Ivo Domingues ${ }^{1}$ \\ ORCID: 0000-0002-0976-0247 \\ Maria José Costa ${ }^{1}$ \\ ORCID: 0000-0002-7783-4789
}

\section{Resumo}

Este estudo analisa literatura sobre governança escolar editada em periódicos da Coordenação de Aperfeiçoamento de Pessoal de Nivel Superior (CAPES), classificadas com o indicativo da qualidade 'A1'. Enquadra-se na sociologia das organizações educativas e tem natureza exploratória, aproximando-se da forma de meta-análise. Oferece uma análise objetiva da literatura científica produzida sobre este tópico. Esta análise caracteriza a literatura editada em português, de autores lusófonos e não lusófonos, quanto aos objetivos científicos, à natureza e orientação teórica, à composição dos quadros teóricos de análise, bem como à estratégia de investigação. Para construir sentido analítico sobre as conclusões e propor uma explicação sociológica, foram usados os conceitos de reificação, afınidade eletiva, neutralidade axiológica e habitus científico. Este artigo tem impactos teóricos, na medida em que sublinha a natureza reducionista da investigação realizada, e práticos, na medida em que propõe reconceptualização do objeto empírico. A análise produzida permite caracterizar esta literatura como sendo ambivalente, porque é conservadora nos processos científicos e crítica no objeto científıco, não filiável em paradigmas de análise científıca, orientada mais para a dedução teórica do que para a indução empírica, privilegia o nível macro face aos níveis meso e micro, adota métodos de pesquisa empírica insuficientemente controlados, revela tendência teórica reificadora, é afetada por afinidades eletivas e desafia a neutralidade axiológica. Por fım, questiona-se a importância e utilidade da ciência para a compreensão e transformação da governança educacional.

\section{Palavras-chave}

Gerencialismo - Governança - Método - Reducionismo teórico.

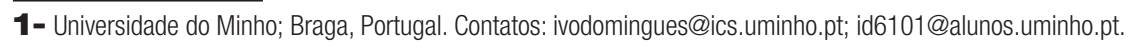




\section{Scientific investigation of education governance: empirical and theoretical trends}

\section{Abstract}

This study analyses literature concerned with school governance published in the last two decades in journals classified as 'A1' by CAPES (a Brazilian public organisation in charge of the coordination for the improvement of higher education personnel). The study is based on the sociology of organisations and performs an exploratory approach, with a proximity with meta-analysis. It analyses the literature edited in Portuguese and focuses on several scientific dimensions (scientific goals, research nature, theoretical frameworks and research strategy). The research method is qualitative by nature, and it involves secondary sources (papers). The papers are the corpus and were selected according to the random systematic sampling technique. The theoretical framework involves several concepts: reification, axiological neutrality, and scientific habitus; furthermore, it proposes the 'militant science' concept to typify the analysed science that integrates the empirical corpus. The main findings show some critical findings related to the scientific literature taken as a research object: it is ambivalent, not based on theoretical frameworks, prioritizes theoretical deduction rather than empirical induction, as well as macro-level rather than meso- and micro-levels of analysis; uses scientific methods insufficiently controlled, tends to reification approaches; it is affected by elective affinities and devalues the axiological neutrality.

\section{Keywords}

Governance - Managerialism - Research strategy - Theoretical reductionism.

\section{Introdução}

As últimas duas décadas foram caracterizadas por profundas mudanças no sistema educativo não superior. Esta mudança foi animada por diversos fatores. A orientação normativa reguladora tem sido inspirada em contexto de crise financeira dos Estados e na redefınição do papel do Estado nas sociedades democráticas. 0 Estado passou de responsável a promotor e regulador do desenvolvimento (CABRAL NETO; CASTRO, 2011; GOULART; PINTO; CAMARG0, 2017), mudança inspirada no neoliberalismo baseado na globalização e na privatização (ANTUNES; PERONI, 2017; ROBERTSON, 2013), bem como na perspectiva mercadocêntrica (NEWMAN; CLARKE, 2012; ROBERTSON; VERGER, 2012). Esta mudança implicou o reforço de regulação (HYPOLITO, 2010) e a melhoria da administração pública na efıcácia e na eficiência (TRIPODI; FIGUEIRED0; SOUSA, 2016). As transformações no sistema educativo são significativas na direção e gestão dos 
sistemas de ensino e das escolas. Esta reflexão procura analisar a investigação científica que sobre esta transformação foi produzida.

Este estudo tem natureza exploratória. Esta é particularmente adequada para realizar abordagem a objetos insuficientemente estudados e orienta a pesquisa para “desenvolver, esclarecer e modificar conceitos e ideias" (GIL, 1999, p. 43). Assim, este estudo é orientado para responder ao seguinte problema: qual a abordagem científica que a investigação tem adotado para analisar o impacto da nova gestão pública no ensino pósinfantil e não superior? Os problemas de investigação qualitativa, usualmente, emergem das preocupações teóricas e metodológicas dos investigadores (SILVERMAN, 2001). Na verdade, o problema de investigação aqui adotado emergiu de impressão empírica (a literatura científica editada em português é tendencialmente teórica) e de uma necessidade teórica (conhecer as tendências da literatura sobre o tema da governança no subsistema de ensino considerado). 0 problema formulado tem implicações teóricas (caracteriza as teorias dominantes, seu potencial e fragilidade) e metodológicas (caracteriza as estratégias de investigação). Esta investigação adota os seguintes objetivos: i) caracterizar os sistemas teóricos e metodológicos usados na investigação da governança, ii) caracterizar as tendências da investigação no subsistema de ensino considerado e iii) propor explicação sociológica das características identificadas.

\section{Abordagem teórica}

A análise das fontes é baseada nas abordagens teóricas e nas teorias. As abordagens teóricas são orientações gerais para o objeto sociológico (GIDDENS, 1989), enquanto as teorias são explicações dos objetos sociológicos e são influenciadas pelos resultados de investigação (GIDDENS, 1989). Quanto à explicação do objeto, a abordagem teórica pode ser 'idiográfica', quando foca fatos de um só caso e explica muito acerca de pouco, ou 'nomotética', quando foca fatos em muitos casos e explica pouco acerca de muito (BERNARD, 2000). Quanto à relação teoria-empiria, a abordagem pode ser 'dedutiva', quando é desenvolvida a partir da teoria para melhorar o conhecimento científico através de dedução e 'indutiva', quando é desenvolvida a partir de observações empíricas para gerar teoria através de indução (BRYMAN, 2004). Quanto à natureza do pensamento, a abordagem pode ser 'holística', quando foca as relações entre as partes, incluindo padrões e sequências relacionais, influência mútua e dinâmica, autonomia e interdependência; 'bipolar', quando foca interdependências entre oposições polares, evitando reducionismos; 'determinista', quando foca relações causais lineares ou mesmo leis (HERON, 1998). Estes tipos de abordagens não são substitutivos, pois exploram diferentes critérios. Neste estudo: i) identificamos as abordagens teóricas adotadas para estudar a governança escolar; e ii) caracterizamos a coerência entre estas e os métodos de investigação da governança escolar.

As teorias explicam os resultados empíricos dos fenômenos estudados. A micro-teoria foca o comportamento interativo das pessoas, envolvidas em encontros diários, enquanto a macro-teoria foca o comportamento de massas de pessoas que compõem os sistemas sociais (MAY, 2001); a perspectiva micro tende a ser associada a contextos da interação, enquanto a perspectiva macro tende a ser associada à sociedade ou a instituições sociais 
(SIBEON, 2004). A relação entre estes dois níveis pode ser articulada pela meso-teoria, a qual foca as organizações. Ao adotar a organização como uma unidade de análise, os estudos podem abordar os indivíduos, os processos organizacionais e as interconexões ambientais, incorporando os níveis micro, meso e macro da explicação (VAUGHAN, 2002); por isso, a análise do nível meso permite melhorar a coerência dos sistemas teóricos que analisam a relação entre os níveis micro e macro (HOUSE; ROUSSEAU; THOMASHUNT, 1995). Consequentemente, quanto aos níveis de análise, a abordagem pode ser 'macro', quando foca os modelos de governança e as políticas educativas e gestionárias; 'meso', quando foca a codificação das orientações globais nas escolas e os processos de participação na governança; e 'micro', quando foca as interações entre participantes na educação. Neste estudo: i) identificamos os níveis de análise focados; e ii) caracterizamos as relações entre si estabelecidas.

A teoria realiza diferentes funções na pesquisa científica. Concretamente, explica generalizações empíricas conhecidas e prediz generalizações empíricas ainda desconhecidas (WALLACE, 1971; BREWER; HUNTER, 1989); estas funções - explicação e predição materializam paradigmas alternativos para construir teorias (BERNARD, 2000). A teoria determina a importância dos fatos e restringe aqueles a serem estudados, conceitualizaos e classifica-os com base em sistema de conceitos, resume o conhecimento científico do objeto empírico, identifica lacunas no conhecimento científico e prevê fatos (GOODE; HATT, 1973). Assim, a teoria organiza as pesquisas científicas sobre a governança escolar segundo os seus fins. Neste estudo: i) identificamos as teorias convocadas para analisar a governança; e ii) caracterizaremos os seus fins analíticos.

Os conceitos são os elementos básicos da teoria. Conceitos são termos abstratos usados para criar sentido sobre as experiências sociais (BAKER, 1998) e que encapsulam um modo de pensar acerca de um fenômeno social (MATHEWS; ROSS, 2010) para o qual a pesquisa é dirigida (BRYMAN, 2004); são construções lógicas criadas com base em impressões, perceções ou mesmo vivências (G00DE; HATT, 1973) ou derivados de modelos teóricos que, em conjunto, formam teorias que defınem e explicam um fenômeno (SILVERMAN, 2000), viabilizam e limitam a teorização (KAPLAN, 1964); o seu poder de compreensão é tanto maior quando mais suportam a construção de teoria que explica os resultados empíricos (BERNARD, 2000). Em suma, a teoria é conjunto de conceitos e de relações proposicionais entre conceitos que constituem um modelo da realidade (MAXWELL, 2005). Na verdade, eles são propriedades das relações sociais da produção de conhecimento e o seu poder assenta na sua capacidade para persuadir e influenciar ou para vencer a lógica e evidência de outros conceitos concorrentes (ALFORD; FRIEDLAND, 1992). A análise dos conceitos usados na construção teórica permite, assim, identificar as dimensões da governança abordadas. Neste estudo: i) identificamos os conceitos convocados; e ii) caracterizamos as relações estabelecidas entre eles.

\section{Método}

Os métodos medeiam a relação dos princípios da teoria e das crenças dos investigadores com o objeto empírico estudado. A teoria é interpretação e a metodologia 
é ação dos sociólogos no seu ambiente (DENZIN, 1989), enquanto o método indica conjuntos de técnicas específicas usadas para estudar dado fenômeno (SILVERMAN, 2000, 2001). Nesta pesquisa, a metodologia é qualitativa e o método é a análise de conteúdo. Esta é aplicável a qualquer nível de investigação empírica, sendo portadora da vantagem de ser 'não obstrutiva', ou seja, não gerar enviesamentos na produção de dados (VALA, 1986). A investigação realizada inspira-se nas técnicas da análise da enunciação e da análise proposicional do discurso, como as apresenta Bardin (2009), e é servida pela inferenciação, enquanto combinação de elementos textuais e/ou elementos contextuais para analisar o que é implícito e explícito no texto e, deste modo, criar um novo significado (SHIRO, 1994).

A confiabilidade e a validade são requisitos da qualidade da pesquisa qualitativa. A confiabilidade é requisito da pesquisa qualitativa e consiste na consistência da codificação dos dados por diferentes pesquisadores (HAMMERSLEY, 1992; BAUER, 2000) e os textos são, em princípio, dotados de mais elevada confiabilidade do que as observações (SILVERMAN, 2001). A validade é requisito da pesquisa qualitativa e consiste no controle preventivo de fatores mentais que afetam a produção ou/e a análise dos dados (SILVERMAN, 2001), o grau em que os resultados representam o texto ou o seu contexto (BAUER, 2000); a validade interna e externa constitui requisito complexo, cuja conformidade pode ser afetada por diversos fatores (ONWUEGBUZIE; LEECH, 2007). 0 reforço da validade interna e externa na pesquisa qualitativa pode ser assegurado, entre outras, pelas técnicas de triangulação (ONWUEGBUZIE; LEECH, 2007) e pela definição das categorias de análise, a qual deve ser suficientemente precisa para permitir a diferentes codificadores chegarem ao mesmo resultado (SILVERMAN, 2001). Tanto a validade como a confiabilidade dependem das habilidades metodológicas, da sensibilidade e da integridade ética do investigador (PATTON, 1990). Assim, confiabilidade e validade são requisitos fundamentais e dependem muito do processo de pesquisa.

Neste estudo, asseguramos estes requisitos da qualidade da pesquisa pelos instrumentos de análise adotados, pela definição objetiva das categorias de análise e pela triangulação de codificadores e da codificação dos dados. Os instrumentos de análise categorial foram construídos por dedução, baseada na análise da teoria sobre investigação. Os artigos que compõem a amostra foram totalmente lidos, sinalizados os conteúdos que correspondiam a categorias de análise e registados na folha de conteúdo correspondente de planilha 'Excel'. A análise dos textos e categorização dos dados foi processada pelos autores em separado, na primeira fase, e cotejados e discutidos os resultados, quando diferentes, na segunda fase; este processo foi repetido um mês depois. Sempre que houve diferenças de resultados, estas eram analisados em conjunto para melhorar a objetividade da categorização. Assim, realizamos triangulação de codificadores e de processos de codificação.

Nesta pesquisa, caracterizamos a investigação científıca publicada sobre a governança do sistema de ensino e propomos explicação de natureza teórica sobre os resultados empíricos obtidos. As fontes são secundárias e consistem em revistas científicas publicadas em português, da área da educação, classificadas como 'tipo A1' pela CAPES (entidade brasileira que gere os recursos financeiros públicos diretamente aplicados à valorização da investigação). Assim, trata-se de meios de divulgação científica muito valorizados naquela comunidade científica, pois serão representativas da melhor investigação editada em português. 
Nestas revistas, foram procurados artigos que, no título e nas palavras-chave, incorporassem os conceitos 'governança', 'gerencialismo' ou/e 'managerialismo'. A constituição do 'corpus' da pesquisa é fase de pré-análise (BARDIN, 2009); este é constituído por artigos que foram editados em 9 revistas 'tipo A1'. Ao todo, foram identificados 35 artigos; este universo é composto de 9 artigos de autores não lusófonos e 26 artigos de autores lusófonos. A amostra é composta de 18 artigos, correspondendo a 51\% do universo; é equitativamente constituída por 9 artigos de autores lusófonos e não lusófonos; a amostragem dos textos não lusófonos é acidental e a amostragem dos textos lusófonos é teórica; a primeira resulta da identificação dos textos existentes nas revistas identificadas; a amostragem teórica resulta, quanto à dimensão, do critério da igualdade para assegurar maior homogeneidade à base da comparação teórica e, quanto à escolha dos artigos, resulta da necessidade de segmentar dados de acordo com os sistemas de categorias adotados na categorização por dedução.

\section{Resultados}

Recorremos à formação de sistemas de categorias para ajudar na construção de sentido mais objetiva. As categorias são conceitos que emergem dos dados (STRAUSS; CORBIN, 1998). Por isso, usamo-las para objetivar e tipificar a realidade expressa nos dados.

A abordagem teórica e metodológica é diversa (ver tabela 1 - Teoria e método). Quanto à natureza, todos os estudos têm orientação teórica e cerca de metade (8 de 18) tem base empírica formal. Quanto à orientação, manifestamente, nenhum tem orientação confirmatória e apenas um tem orientação exploratória, a qual não é empírica. Quanto à estratégia de investigação, não são idiográficos nem nomotéticos, ou seja, não pretendem analisar intensa e globalmente um caso nem analisar extensa e parcialmente vários casos; não há estudos de múltiplos casos assumidos e, quando eles são tácitos, a análise extensiva não é seu objetivo; existem apenas dois estudos de caso, os quais correspondem a unidades geo-administrativas - Estados do Brasil. Quanto ao método de pesquisa empírica, pequena parte recorre ao método quantitativo ( 2 de 8 ) e os restantes recorrem ao método qualitativo; no caso dos estudos quantitativos, estes apenas recorrem a análise estatística descritiva; no caso dos estudos qualitativos, não são especificadas as técnicas de análise de conteúdo usadas. Quanto às fontes, tendencialmente, são secundárias, concretamente relatórios de instituições, documentos legais, relatórios estatísticos nacionais e relatórios do Banco Mundial; as fontes primárias são consultadas por meio de entrevista e de questionário. Assim, a produção científica tende a ser holística, embora de intensidade variável; a bipolaridade de leituras teóricas, muitas vezes latentemente presente, não constitui objeto ou instrumento analítico; a abordagem determinista é totalmente ausente pois, embora haja alguns estudos quantitativos, estes não testam relações entre variáveis; os artigos que objetivam a empiria recorrem sobretudo a fontes secundárias. A diferença relevante entre os grupos de investigação lusófonos e não lusófonos consiste na existência de mais estudos empíricos no grupo de autores lusófonos. 


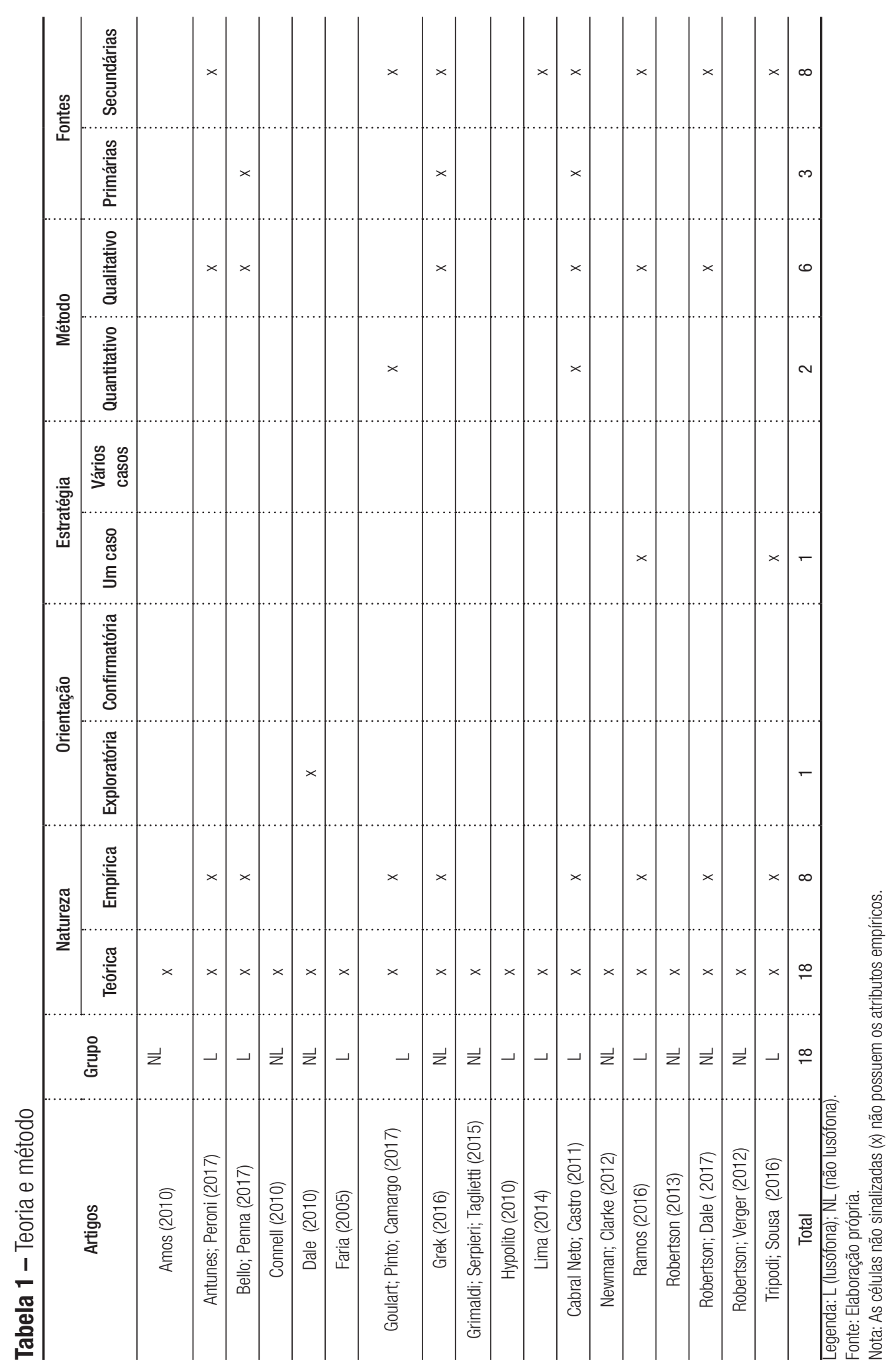




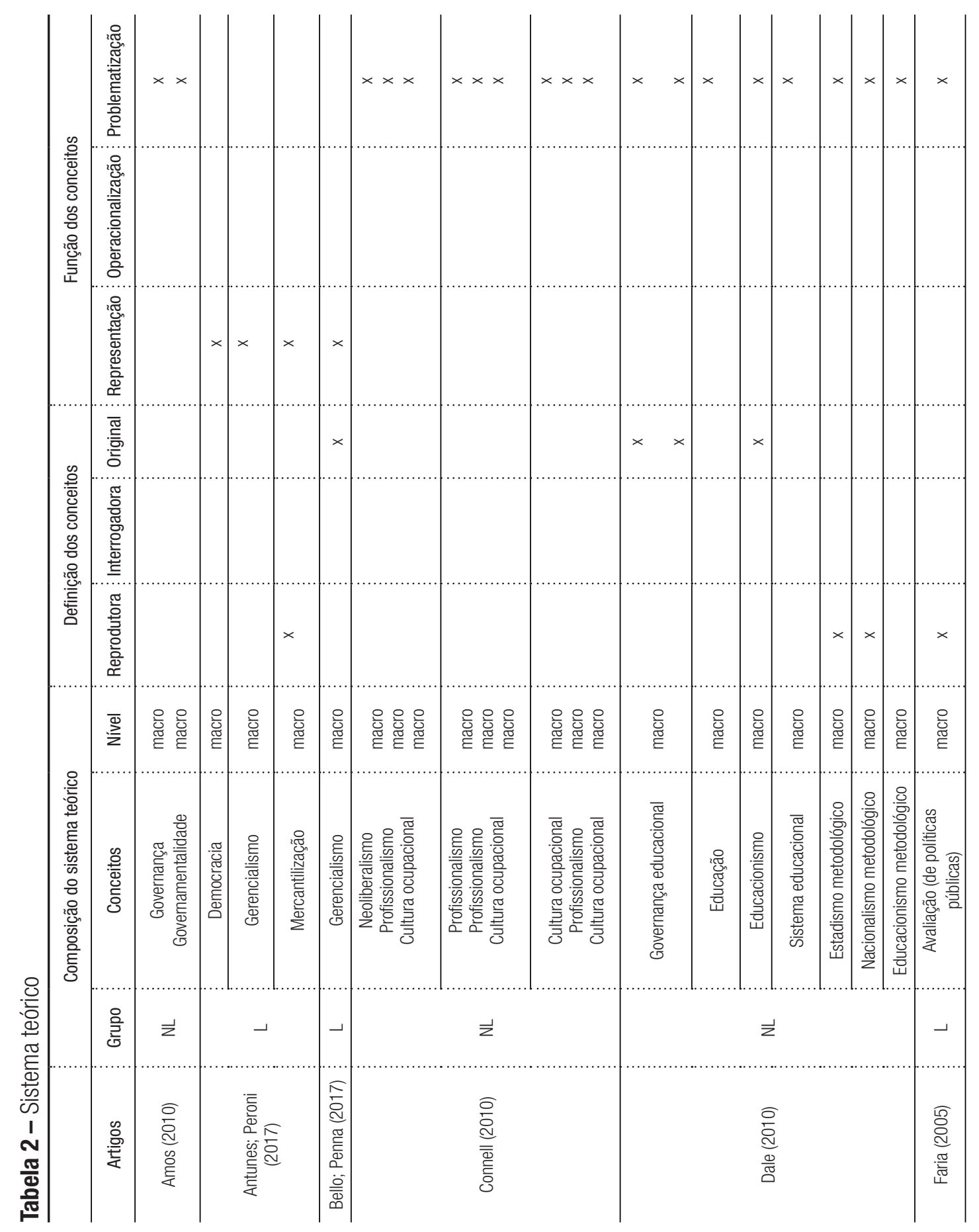




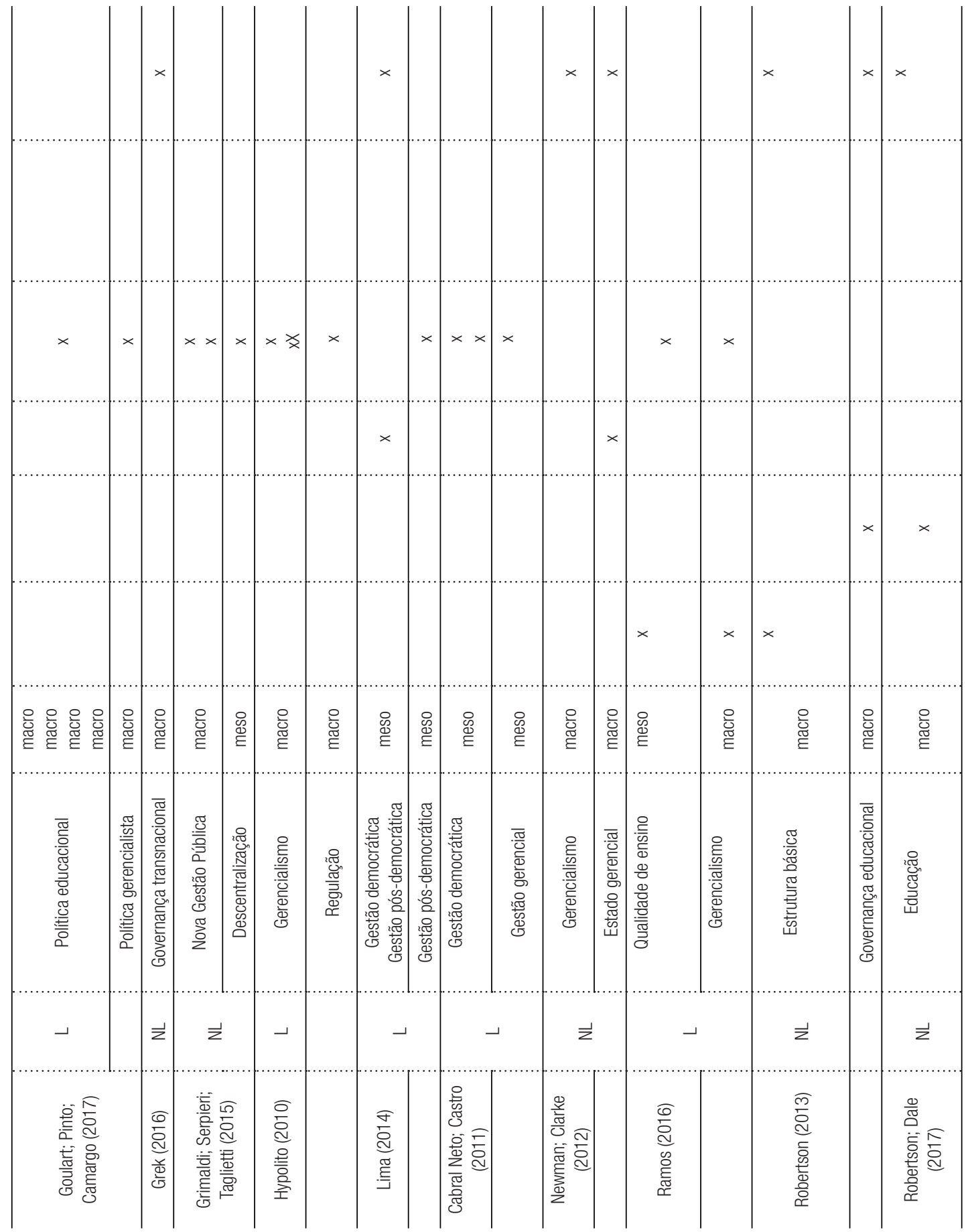




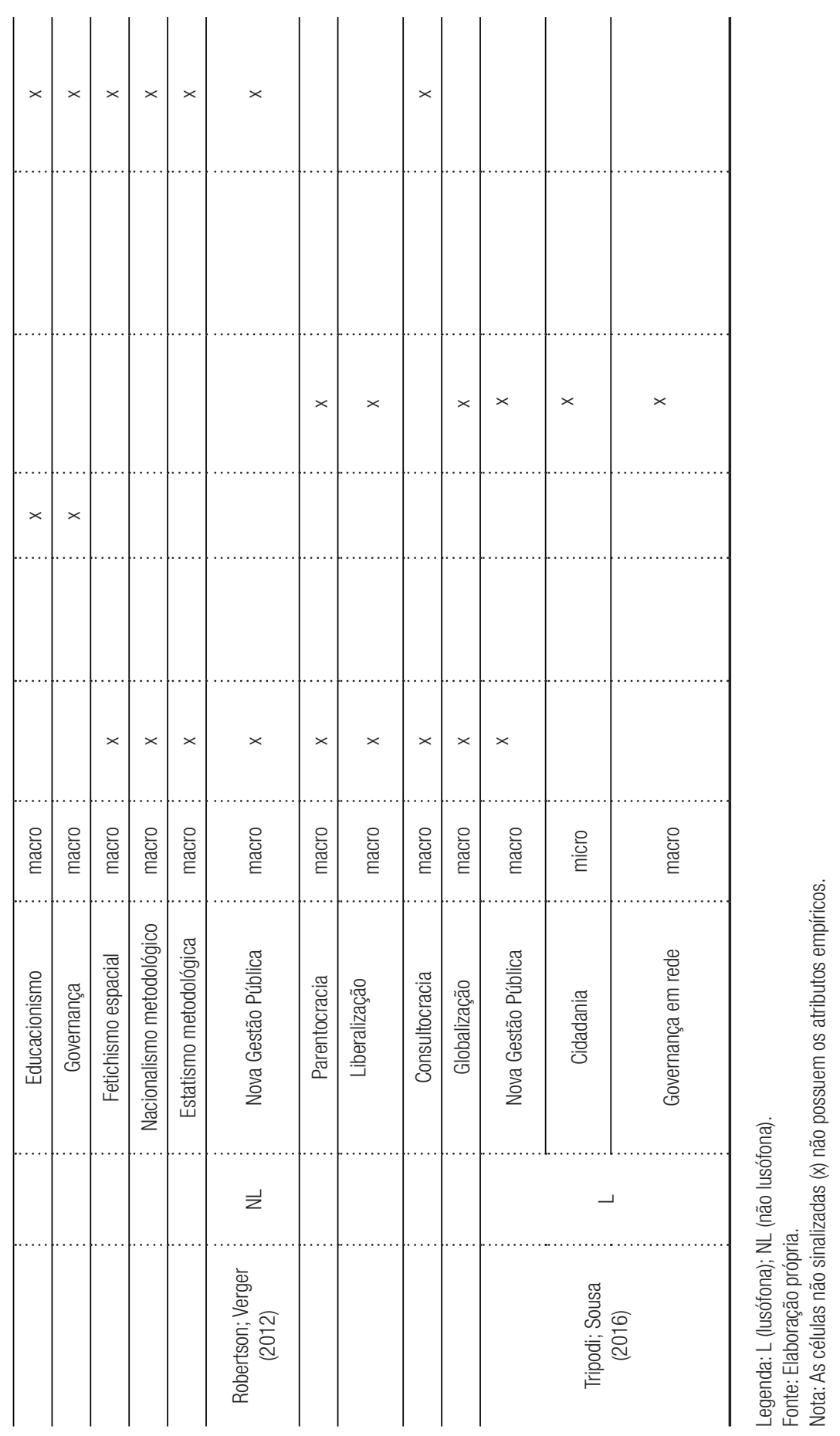


Os sistemas teóricos oferecem os instrumentos de análise (modelos, teorias e conceitos) dos objetos empíricos abordados (ver tabela 2- Sistema teórico). A literatura revista apresenta raridade de modelos teóricos e de teorias e abundância de conceitos. Por isso, restringimos a análise aos conceitos. Para os fins desta análise, adotamos este sistema de categorias conceituais: 'reprodutora', quando aplica conceitos existentes sem o interrogar o seu valor hermenêutico; 'interrogadora', quando define os conceitos e questiona o seu valor hermenêutico; 'original', quando a definição dos conceitos é alternativa ou pioneira. Quanto à função dos conceitos e teorias, adotamos este sistema de categorias: 'representação', a qual consiste na aplicação dos instrumentos teóricos à realidade empírica para a identificar e nomear e/ou para caracterizar o seu estado e tendências; 'operacionalização', a qual consiste na definição de constructos teóricos e na sua objetivação para observação; 'problematização', a qual consiste na interrogação da teoria e/ou da empiria para analisar fragilidades teóricas e/ou características empíricas. Quando existem funções acumuladas, optamos pelo registo da que é teoricamente mais complexa; consideramos que a complexidade dos conceitos é, quanto aos fins e quanto às funções, progressiva e crescente, ou seja, a sequência da sua apresentação indicia a sua complexidade crescente.

A definição dos conceitos é diversa e assimétrica. Dos conceitos usados, cerca de metade é definida (25 de 48); dos conceitos definidos, a maior parte é reprodutivamente definida (16 de 25), pequena parte é originalmente definida (7 de 25) e a parte interrogativamente definida é irrelevante (2 de 25). Assim, a definição dos conceitos não é regra dominante e, quando realizada, ela é, tendencialmente, conservadora e não crítica. Quanto à função teórica, nenhum dos conceitos é operacionalizado como constructo para facilitar a compreensão e explicação; diferentemente, são aplicados para problematizar (27 de 48) ou para representar a realidade (21 de 48). Assim, a utilização dos conceitos não é orientada para pesquisas empíricas propiciadoras da sua testagem, mas para suportar análise problematizadora e representacional da realidade. A função teórica dominante destes estudos é analítica, sendo complementada pela função explicativa teórica. Para os fins desta análise, a explicação é categorizada como 'explicação subsidiária', quando agrega valor à teoria existente com base na análise empírica, e como 'explicação subsidiada', quando convoca teoria existente para analisar a realidade empírica. Na grande maioria dos casos analisados, a explicação produzida é subsidiada.

Existem algumas diferenças significativas entre os grupos científicos. Quanto à distribuição de frequências: a média aritmética de conceitos por artigo é de 2,7 na totalidade da amostra; entre os autores não lusófonos e lusófonos, a média é de 3,3 e 2,0 conceitos por artigo, respectivamente. Quanto à distribuição das definições conceituais segundo a natureza dos grupos científicos, não há grande diferença proporcional, pois as definições são na razão de 7 de 18 e 18 de 30 dos casos para autores lusófonos e não lusófonos, respetivamente; quanto à natureza da definição de conceitos, a maior parte das definições originais ( 5 de 7) e as definições interrogadoras (2 de 2) ocorrem na literatura não lusófona. Quanto às funções teóricas dos conceitos, a função representacional domina na literatura lusófona (16 de 22) e a função problematizadora domina na literatura não lusófona (24 de 26). Assim, os artigos de autoria não lusófona são escorados em maior quantidade 
de literatura, são conceptualmente mais densos e criativos, ambas as comunidades de autores aplicam conceitos de modo reificado, mas os autores não lusófonos apreciam mais criticamente os conceitos que usam. Uma característica comum e adicional é a pouca importância concedida à revisão formal da literatura.

Os estudos revelam distribuição muito assimétrica dos conceitos pelos níveis de análise. A distribuição de frequências no total dos conceitos é a seguinte: nível macro (41 de 48), nível meso (6 de 48) e nível micro (1 de 48); na perspectiva macro, os conceitos governança, gerencialismo, nova gestão pública e gestão democrática totalizam quase metade dos conceitos desta categoria. Assim, os conceitos associados a modelos de gestão do sistema educativo dominam a perspectiva macro. A proporção da frequência dos conceitos definidos em relação ao total de conceitos definidos, por níveis de análise, é a seguinte: macro (23 de 25), meso (2 de 25) e micro (0 de 25). A distribuição dos conceitos pelos níveis de análise dentro dos dois grupos de cientistas é a seguinte: entre os textos de autores lusófonos, macro (12 de 18), meso (5 de 18) e micro (1 de 18); entre os textos de autores não lusófonos, macro (29 de 30), meso (1 de 28) e micro (0 de 28). Esta análise permite enfatizar as seguintes características: a preferência pela perspectiva macro é dominante em ambos os grupos, sendo maior entre os autores não lusófonos, e a preferência pela perspectiva meso é maior entre os autores lusófonos; a proporção de conceitos definidos é relativamente baixa, o que sugere existência de aplicação reificada destes instrumentos analíticos; os níveis de análise não são formalmente anunciados e, consequentemente, as relações entre as realidades produzidas neles ou entre eles partilhadas, por influência ou sequência, não são explícitas; quando existem relações entre níveis, a sua fonte dinâmica é colocada no nível macro. Deste modo, as produções realizadas pelos agentes nos níveis meso e micro são reflexo dos constrangimentos estruturais produzidos no nível macro. A consideração implícita daqueles níveis de análise e das suas inter-relações decorre de estratégia de análise holística genérica, a qual é reducionista. Na verdade, na literatura analisada subjazem concepções de inspiração estruturo-funcionalista e marxista, não assumidas nem formalizadas, as quais assentam em modelos teóricos reducionistas centrados no nível macro.

\section{Discussão}

A revisão da literatura é tarefa imprescindível do processo científico. Para efeito desta análise, a revisão é classificada com base no critério 'abordagem da teoria', o qual é distinto do critério 'abordagem teórica'. As categorizas são as seguintes: 'abordagem reprodutora', a qual convoca conceitos que usa sem avaliar criticamente o seu valor hermenêutico para analisar o objeto empírico; 'abordagem crítica', a qual avalia o valor hermenêutico de teoria ou de conceitos para analisar a realidade empírica. Tendencialmente, a abordagem da teoria e conceitos é reprodutora e acrítica. A abordagem crítica mais marcada da teoria discute o valor de conceitos para a educação comparada (AMOS, 2010) e sublinha a necessidade de abordar objetos macro (nacional, educação e sistemas) segundo perspectiva que previna a fetichização destas concepções (DALE, 2010). Assim, a abordagem da teoria é, tendencialmente, ambivalente: por um lado, ela é conservadora e orientada para a aplicação acrítica de instrumentos teóricos; por outro lado, produz leitura 
crítica da realidade empírica. Esta ambivalência exercerá uma função analítica latente: a abordagem acrítica da teoria facilita a abordagem crítica da empiria.

Em pequena parte da literatura analisada é adotada perspectiva crítica manifesta. Concretamente, a análise crítica foca a nova gestão pública (GRIMALDI; SERPIERI; TAGLIETTI, 2015), a interferência do setor privado na educação pública através de parcerias público-privadas (PERONI; CAETANO, 2016), a estreiteza da avaliação institucional concebida e aplicada no âmbito do gerencialismo (FARIA, 2005), a desvalorização de dimensões basilares da gestão democrática das escolas (LIMA, 2014) e a metodologia de comparação de políticas educacionais (ROBERTSON; DALE, 2017). Contudo, apenas neste último caso é expressamente adotada perspectiva crítica consagrada - a realista crítica. 0 realismo crítico combina o realismo ontológico, o relativismo epistemológico e a racionalidade do julgamento (ARCHER et al., 1998), oferecendo uma terceira via entre o empiricismo e o positivismo e entre o relativismo e a redução interpretativista baseada em leis (SAYER, 2000). Assim, nestes estudos é notória a generalizada ausência de referência paradigmática teórica formalmente expressa que organize e padronize o labor científico nos termos do paradigma adotado e, desse modo, normalize a produção do conhecimento.

Diversos estudos consideram a relação entre os níveis de análise. A literatura representa estes níveis do seguinte modo: macro (Estado, Nova Gestão Pública, neoliberalismo, mercado, contratos-programa); meso (organizações escolares, parcerias público-privadas, individualização dos contratos de trabalho, avaliação de desempenho); micro (participação de indivíduos ou agentes, relação entre estes e as instituições, práticas educativas). A relação macro-meso é estabelecida pelas políticas públicas (ANTUNES; PERONI, 2017), pela gerencialização e governança em rede (NEWMAN; CLARKE, 2012), pelo planeamento e regulação estratégica (ROBERTSON; VERGER, 2012), pelas ideias e tecnologias autonomizadoras, responsabilizadoras e reguladoras (GRIMALDI; SERPIERI; TAGLIETTI, 2015), por parcerias interorganizacionais (PERONI; CAETANO, 2016), pela orientação dos estudos de avaliação de impacto das políticas públicas (FARIA, 2005), pela política educacional e pela governança e pedagogia (AMOS, 2010), e pela formação de professores (CONNELL, 2010). Nestes casos, os articuladores dos níveis de análise pertencem às políticas educativas, administrativas e pedagógicas, às tecnologias administrativas e regulatórias, ou seja, têm natureza impessoal. Os agentes, as suas estratégias e práticas de gestão e participação na administração escolar não são focados. Contudo, há imperfeitas exceções. A relação macro-meso-micro é estabelecida e realizada pela governança por números (GREK, 2016), pelas parcerias público-privadas (ROBERTSON, 2013), pelo ideário revolucionário em contexto de ruptura de regime político-administrativo e, após esta fase, pela política de educação (LIMA, 2014). Assim, mesmo quando a análise toca os niveis meso e micro, as orientações e práticas dos agentes não são consideradas. Nesta perspectiva, a administração escolar é mais produto do que processo e as pessoas são mais instrumentos do que agentes.

A literatura revista não apresenta nenhum estudo de caso tipicamente classificável como tal. Há estudos de caso, de natureza geo-administrativo-política, correspondendo ao estado de Minas Gerais (TRIPODI; SOUSA, 2016) e ao Estado de São Paulo (RAMOS, 2016), mas que não são conformes com os requisitos da estratégia de estudo de caso; há estudos de múltiplos casos (BELLO; PENNA, 2017; ANTUNES, PERONI, 2017), mas 
também não conformes com a estratégia de estudo de caso. Os estudos qualitativos existentes são mais facilmente como tal classificáveis. A classificação de estudos quantitativos é mais difícil, pois há estudos de orientação quantitativa, focado na caracterização da elaboração dos projetos político-pedagógicos (CABRAL NETO; CASTRO, 2011) e na reorganização da rede pública de ensino (GOULART; PINTO; CAMARG0, 2017), os quais são, respectivamente, restritos a cálculo de frequências e proporções e a frequências retiradas de fontes secundárias; falta-lhes, portanto, o virtuosismo estatístico normalmente convocado para este tipo de estudos. Assim, as estratégias de investigação são incaracterísticas. Esta limitação tem efeitos teóricos e práticos: por um lado, dificulta a replicação dos estudos e a acumulação de conhecimento científico externamente validado e que legitima a teoria; por outro lado, não promove a revisão política do modelo de governança baseada na ciência.

0 ametodismo é propriedade dos estudos realizados, consistindo na ausência ou na incompletude de método. Foram identificados dois tipos de ametodismo: o 'ametodismo conforme', correspondente a ausência ou insuficiência de método justificada pela natureza exclusivamente conceitual do estudo, e o 'ametodismo não conforme', correspondente a ausência ou insuficiência de método não justificável pela opção teórica do estudo. No primeiro caso, ele é inerente à natureza do estudo; no segundo caso, ele decorre de vício de forma ou de processo. Na quase totalidade dos casos ametódicos, o ametodismo é conforme, o qual é beneficiado pela limitada ambição da análise de conteúdo das fontes secundárias qualitativas, a qual, por exemplo, não arrisca análise estrutural discursiva ou análise comparativa. 0 ametodismo não conforme é mais visivel em estudos que recorrem a fontes primárias, como acontece na não identificação/caracterização das técnicas de análise de conteúdo de fontes secundárias (TRIPODI; SOUSA, 2016; GREK, 2016) e não quantificação do universo, não identificação do critério de amostragem nem do tipo de entrevista (BELLO; PENNA, 2017). De modo geral, nos artigos analisados, o método é pouco valorizado, não recebendo estatuto de seção específica, podendo até ser apresentado em nota de rodapé no final do texto. Assim, a desvalorização do método e as práticas metodológicas não conformes dificultam a replicação objetiva das pesquisas realizadas noutros contextos sócio-organizacionais e reduzem a validação externa dos seus quadros teóricos e dos resultados.

Existe tendência para adoção de perspectiva reificadora. Reificação significa o uso de conceitos abstratos desconectados das práticas concretas dos agentes (LUKACS, 1971), a falácia de tratar convenções, instituições e eventos como produtos de processos recursivos ou leis universais (HARVEY; REED, 1997), de perspectivar os produtos da ação humana como resultados não humanos (BERGER; LUCKMANN, 1966). A consequência da reificação conceitual é a multiplicação não controlada dos usos dos conceitos (LANE; KOKA; PATHAK, 2006), a qual pode ser prevenida quando a pesquisa permite, simultaneamente, aplicar e interrogar os conceitos (WELCH; RUMYANTSEVA; HEWERDIN; 2016). A literatura revista tende a ser afetada por reificação teórica. Por um lado, tácita ou explicitamente, aceita que o modelo da gestão democrática é modelo desejável sem esclarecer os princípios teóricos e/ou valores morais adotados como referenciais, nem questionar a sua eficácia e eficiência. Por outro lado, aceita que o modelo gerencialista é modelo indesejável sem 
equacionar os seus princípios teóricos e/ou valores morais de referência nem esclarecer a sua efıcácia e eficiência. Assim, a valorização e desvalorização implícita de modelos de gestão refletirá modelos da administração pública e escolar tacitamente (des)valorizados e inibe possibilidades de melhoria da teoria no confronto com a empiria.

A ciência disponibilizada é produto de afinidade eletiva. Weber (1978) convocou este conceito para expressar a relação entre razão econômica e ética religiosa, e entre estruturas concretas da ação social e formas concretas de organização econômica. Ele usa a concepção de afınidade eletiva para indicar a natureza contingente das conexões entre o conteúdo simbólico das crenças que os indivíduos elegem seguir e as consequências que essa adesão tem para a vida social (GIDDENS, 1972). Para entender o que é a afinidade eletiva em Weber, é necessário sublinhar que existem possíveis tensões entre ideias e interesses, sendo preferivel associar afinidade à noção de ideia e a eletividade à noção de interesse (GERTH; MILLS, 1982). A literatura produzida procura estabelecer afinidades eletivas entre o nível macro e o nível meso, sobretudo, entre as políticas e a administração educacional, entre os requisitos gerencialistas da nova gestão pública e a mercadorização dos serviços educativos, entre a ideia de indesejabilidade do modelo da nova gestão pública e o interesse no modelo de gestão democrática.

As fronteiras entre a prática científica e a opinião política são muitas vezes ambiguamente preservadas. A imparcialidade científica implica a separação entre juízo de fatos e juízo axiológico (de valor), devendo o leitor ser informado onde acaba um e começa outro (WEBER, 1983) porque, como têm origem subjetiva, os juízos de valor não têm lugar na análise científica (WEBER, 1992). Assim, a demonstração científica que seja metodologicamente correta é entendível como correta por uma plateia universal (WEBER, 1983) porque a significação é comum. Uma ciência empírica não permite profecias pessoais (WEBER, 1983) nem prescreve o que fazer (WEBER, 1992). A função da ciência é esclarecer a conveniência dos meios em relação aos fins, determinar as consequências dos meios, apoiar a tomada de consciência sobre a realidade, mas não prescrever decisões (WEBER, 1983). Por isso, adotar uma posição política é atuação política, enquanto analisar as estruturas políticas e as posições partidárias é atuação científica (WEBER, 1982). A literatura produzida revela, em muitos casos, tácita tendência para se colocar em zona onde a neutralidade e a parcialidade axiológica ambiguamente se relacionam.

0 valor da teoria depende do valor do método. As opções empíricas são inseparáveis das opções teóricas (BOURDIEU, 1989) e a teoria, enquanto propiciadora de conhecimento que permite a possibilidade de tratar um problema, carece do método, enquanto atividade pensante do sujeito, pois ambos são elementos indispensáveis do conhecimento complexo (MORIN, 1982). Como vimos, a literatura analisada é, tendencialmente, macro-centrada, estruturalista e ametódica. Esta tendência poderá revelar disposições interiorizadas para a prática científica. 0 'habitus' científico manifesta-se em práticas conformes com as normas da ciência sem ter estas na sua origem (BOURDIEU, 1989) e, assim, a atividade científica é baseada nas disposições reguladas de 'habitus' científico, o qual é produto da incorporação das necessidades e dos constrangimentos estruturais do campo científico (BOURDIEU, 1997). A literatura analisada acentuadamente partilha a tendência para iluminar os aspetos negativos da Nova Administração Pública deduzidos da teoria, 
frequentemente servida por saltos dedutivos, e para desvalorizar a investigação empírica com base em fontes primárias e em fontes secundárias produzidas nos níveis micro e meso. Deste modo, o confronto entre a teoria e a empiria é evitado em favor de uma perspectiva que é, essencialmente, macro-centrada e teórico-deduzida.

A importância concedida à perspectiva crítica não manifesta, à desvalorização dos agentes, ao ametodismo não conforme, à perspectiva reificadora e à afinidade eletiva parecem convocar a noção de ciência militante. Os aparelhos ideológicos do Estado exercem função reguladora, mas não se confundem com o Estado, como acontece com o sistema de ensino (ALTHUSSER, 1999). Nas organizações de ensino superior, esta condição facilita ou promove a emergência de perspectiva militante da ciência. Nos seus processos administrativos, a atenção e classificação tornam-se invisíveis por meio da socialização, hábito e ideologia (TAYLOR, 1986) e, nos seus processos de investigação, a posição ideológica condiciona a orientação de pesquisa (BROWN; RAJESH, 1983). Assim, as universidades integram o aparelho ideológico do Estado podendo, por isso, absorver e refletir as contradições sociais, o que, associado à difícil separação entre ideologia e investigação científica, pode estimular o desenvolvimento de ciência militante. Esta opção ativista da ciência pode ser facilitada por 'habitus' acadêmicos e por suspensão da neutralidade axiológica, o que, latente ou manifestamente, permite tomar posição ideológica em questões de reforma de modelos de gestão de organizações integradas no aparelho ideológico do Estado. Contrariamente, a percepção da ciência e do ensino da ciência como militantes, quando a militância é adversa à facção social que domina o aparelho de Estado, pode estimular emergência de políticas de controle da administração universitária e de redução do financiamento da investigação científıca, sobretudo nas ciências onde a militância poderá ser mais expressiva.

Esta perspectiva militante não é universal e há quem proponha ruptura com a sua orientação. 0 pensamento sociológico revela-se na capacidade para reconstruir cientificamente objetos socialmente importantes (BOURDIEU, 1989) e a ruptura epistemológica permite suspender as pré-construções, o que implica ruptura com modos de pensar, conceitos e métodos que têm a aparência do bom senso científico (BOURDIEU, 1989). É necessária a reconceptualização da análise sociológica crítica de 'nacional', 'educação' e 'sistema' para melhor entender a educação pós-moderna através da análise das práticas educativas, políticas educacionais, políticas de educação e resultados da educação (DALE, 2010). Focados na gestão e nos meios institucionais de educação, Cabral Neto e Castro (2011) esboçam louvável abordagem empírica do nível meso e micro com base na perspectiva dos agentes, mas o estudo tem ambição analítica limitada à estatística descritiva. É, portanto, fundamental reconceptualizar este objeto, reconhecendo maior capacidade agêntica aos indivíduos que fazem das escolas sítio da sua vida profissional e parental, realizar investigação empírica nos níveis meso e micro que seja metodologicamente legítima e analiticamente ambiciosa. Esta mudança de perspectiva permitirá: i) caracterizar processos de implementação dos modelos de governança nas escolas; ii) compreender as orientações normativas e a interpretação dos requisitos gestionários; iii), avaliar o desempenho do modelo de governança implementado; e iv) explicar os processos e as práticas de participação e de estruturação do modelo de governança. 


\section{Conclusão}

A análise realizada permite formular conclusões de natureza teórica, metodológica e prática sobre os estudos analisados. No plano teórico, domina o reducionismo, pois o nível macro explica os níveis meso e micro e as estruturas determinam a atuação dos agentes; os estudos são mais holísticos do que bipolares e não são deterministas; a explicação científica produzida é mais subsidiada do que subsidiária; as comunidades científicas lusófonas e não lusófonas adotam práticas endógenas de referenciação bibliográfica. No plano metodológico, o reducionismo igualmente caracteriza a produção científıca, pois são poucos os estudos empíricos que recorrem a fontes primárias e a triangulação de fontes; as realidades são mais deduzidas da teoria do que a teoria é induzida pela empiria. No plano da prática, a ausência de competentes estudos nos níveis meso e micro dificulta a melhoria da teoria e a melhoria dos processos de gestão e de participação organizacional. Consequentemente, é necessário reinventar o objeto empírico e inovar o processo científico. A literatura revista também reconhece existência de possibilidades de combinar as orientações crítica e empírica na análise da governança de modo a produzir conhecimento científico que possa ser usado na racionalização do sistema de ensino.

\section{Referências}

ARCHER, Margaret et al. Introduction. In: ARCHER, Margaret et al. (ed.). Critical realism: essentials readings. Abingdon; New York: Routledge, 1998. p. i-xxiv.

ALFORD, Robert R.; FRIEDLAND, Roger. Powers of theory: capitalism, the state, and democracy. 5. ed. Cambridge: Cambridge University Press, 1992.

ALTHUSSER, Louis. Sobre a reprodução. Petrópolis: Vozes, 1999.

AMOS, Karin. Governance and governmentality: relation and relevance of two prominent social scientific concepts for comparative education. Educação e Pesquisa, São Paulo, v. 36, n. esp., p. 23-38, 2010.

ANTUNES, Fátima; PERONI, Vera. Reformas do Estado e políticas públicas: trajetórias de democratização e privatização em educação. Brasil e Portugal, um diálogo entre pesquisas. Revista Portuguesa de Educação, Braga, v. 30, n. 1, p. 181-216, 2017.

BAKER, Thomas, L. Doing social research. 2nd. ed. New York: McGraw Hill, 1998.

BARDIN, Laurence. Análise de conteúdo. Lisboa: Edições 70, 2009.

BAUER, Martin W. Classical content analysis: review. In: BAUER, Martin W.; GASKELL, George (ed.). Qualitative researching with text, image and sound. London; Thousand Oaks; New Delhi: Sage, 2000. p. 131-151.

BELLO, Isabel Melero; PENNA, Marieta Gouvêa Oliveira. 0 papel do coordenador pedagógico nas escolas públicas paulistanas: entre as questões pedagógicas e o gerencialismo. Educar em Revista, Curitiba, esp., n. 1, p. 69-86, jun. 2017. 
BERGER, Peter L.; LUCKMANN, Thomas. The social construction of reality: a treatise in the sociology of knowledge. London: Penguin, 1967.

BERNARD, H. Russell. Social research methods: qualitative and quantitative approaches. Thousand Oaks; London; New Delhi: Sage, 2000.

BOURDIEU, Pierre. 0 poder simbólico. Lisboa: Difel, 1989.

BOURDIEU, Pierre. Razões práticas: sobre a teoria da acção. Oeiras: Celta, 1997.

BREWER, John; HUNTER, Albert. Multimethod research. Newbury Park; London; New Delhi: Sage, 1989.

BROWN, L. David; RAJESH Tandon. Ideology and political economy in inquiry: action research and participatory research. The Journal of Applied Behavioral Science, Sydney, v. 19, n. 3, p. 277-294, 1983.

BRYMAN, Alan. Social research method. 2. ed. Oxford: Oxford University Press, 2004.

CABRAL NETO, Antônio; CASTRO, Alda Maria Duarte Araújo. Gestão escolar em instituições de ensino médio: entre a gestão democrática e a gerencial. Educação \& Sociedade, Campinas, v. 32, n. 116, p. 745-770, jul./set. 2011.

CONNELL, Raewyn. Bons professores em um terreno perigoso: rumo a uma nova visão da qualidade e do profissionalismo. Educação e Pesquisa, São Paulo, v. 36, n. espe., p. 165-184, 2010.

DALE, Roger. A sociologia da educação e o estado após a globalização. Educação \& Sociedade, Campinas, v. 31, n. 113, p. 1099-1120, out./dez. 2010.

DENZIN, Norman K. The research act: a theoretical introduction to sociological methods. New Jersey: Prentice Hall, 1989.

FARIA, Carlos Aurélio Pimenta. A política da avaliação de políticas públicas. Revista Brasileira de Ciências Sociais, São Paulo, v. 20, n. 59, out. 2005. p. 97-110.

GERTH, Hans H.; MILLS, Charles Wright. Introdução. In: WEBER, Max. Ensaios de sociologia. 5. ed. Rio de Janeiro: Guanabara, 1982. p. 9-12.

GIDDENS, Anthony. Capitalismo e moderna teoria social. Lisboa: Presença, 1972.

GIDDENS, Anthony. Sociology. Cambridge: Polity Press, 1989.

GIL, António Carlos. Métodos e técnicas de pesquisa social. São Paulo: Atlas, 1999.

GO0DE, William J.; HATT, Paul K. Métodos em pesquisa social. São Paulo: Nacional, 1973. 
GOULART, Débora Cristina; PINTO, José Marcelino Rezende; CAMARGO, Rubens Barbosa. Duas reorganizações (1995 e 2015): do esvaziamento da rede estadual paulista à ocupação das escolas. Educação Temática Digital, Campinas, v. 19 n. 1, p. 109-133 jan./mar. 2017.

GREK, Sotiria. Atores do conhecimento e a construção de novos cenários de governança: o caso da direçãogeral de educação e cultura da comissão europeia. Educação \& Sociedade, Campinas, v. 37, n. 136, p.707-726, jul./set. 2016.

GRIMALDI, Emiliano.; SERPIERI, Roberto; TAGLIETTI, Danilo. Jogos da verdade. A nova gestão pública e a modernização do sistema educacional italiano. Educação \& Sociedade, Campinas, v. 36, n. 132, p. 759-778, jul./set. 2015.

HAMMERSLEY, Martyn. What's wrong with etnography: methodological explorations. London: Longmans, 1992.

HARVEY, David L.; REED, Michael. Social sciences as the study of complex systems. In: KIEL, L. Douglas; ELLIOTT, Euel (ed.). Chaos theory in the social sciences: foundations and applications. Michigan: University of Michigan Press, 1997. p. 295-324.

HERON, John. Co-operative inquiry: research into the human condition. 2. ed. London: Sage, 1998.

HOUSE, Robert; ROUSSEAU, Denise M.; THOMAS-HUNT, Melissa. The meso paradigm: a framework for the integration of micro and macro organizational behaviour. In: CUMMINGS, Larry L.; STAW, Barry M. (ed.). Research in organizational behavior. v. 17. Greenwich: JAI Press, 1995. p. 71-114.

HYPOLITO, Álvaro Moreira. Políticas curriculares, estado e regulação. Educação \& Sociedade, Campinas, v. 31, n. 113, p. 1337-1354, out./dez. 2010.

KAPLAN, Abraham. The conduct of inquiry: methodology for behavioral science. San Francisco: Chandler, 1964.

LANE, Peter J.; KOKA, Balaji R.; PATHAK, Seemantini. The reification of absorptive capacity: a critical review and rejuvenation of the construct. Academy of Management Review, New York, v. 31, n. 4, p. 833-863, 2006.

LIMA, Licínio C. A gestão democrática das escolas: do autogoverno à ascensão de uma pós-democracia gestionária? Educação \& Sociedade, Campinas, v. 35, n. 129, p. 1067-1083, out./dez. 2014.

LUKACS, Georg. History and class consciousness: studies in marxist dialectics. London: Merlin Press, 1971.

MATHEWS, Bob; ROSS, Liz. Research methods: a practical guide for the social sciences. Harlow: Pearson, 2010.

MAXWELL, Joseph A. Qualitative research design: an interactive approach. 2. ed. Thousand Oaks; London; New Delhi: Sage, 2005.

MAY, Tim. Social research: issues, methods and processes. 3. ed. Buckingham: Open University Press, 2001. MORIN, Edgard. Ciência com consciência. Lisboa: Europa-América, 1982. 
NEWMAM, Janet; CLARKE, John. Gerencialismo. Educação \& Realidade, Porto Alegre, v. 37, n. 2, p. 353381, maio/ago. 2012.

ONWUEGBUZIE, Anthony J.; LEECH, Nancy. Validity and qualitative research: an oxymoron? Quality \& Quantity, v. 2, n. 41, p. 233-249, 2007.

PATTON, Michael Quinn. Qualitative evaluation and research methods. 2. ed. Newbury Pak: Sage, 1990. PERONI, Vera Maria; CAETANO, Maria Raquel. Atuação em rede e o projeto Jovem de Futuro: a privatização do público. Educação \& Realidade, Porto Alegre, v. 41, n. 2, p. 407-428, abr./jun. 2016.

RAMOS, Géssica Priscila. Racionalidade e gerencialismo na política educacional paulista de 1995 a 2014 : muito além das conjunturas. Ensaio, Rio do Janeiro, v. 24, n. 92, p. 546-578, 2016.

ROBERTSON, Susan. As implicações em justiça social da privatização nos modelos de governança da educação: um relato relacional. Educação \& Sociedade, Campinas, v. 34, n. 124, p. 679-703, jul./set. 2013.

ROBERTSON, Susan; DALE, Roger. Comparando políticas em um mundo em Globalização: reflexões metodológicas. Educação \& Realidade, Porto Alegre, v. 42, n. 3, p. 859-876, jul./set. 2017.

ROBERTSON, Susan; VERGER, Amtoni. A origem das parcerias público privada na governança global da educação. Educação \& Sociedade, Campinas: v. 33, n. 121, p. 1133-1156, out./dez, 2012.

SAYER, Andrew. Realism and social science. London; Thousand Oaks; New Delhi: Sage, 2000.

SHIRO, Martha. Inferences in discourse comprehension. In: COULTHARD, Malcolm (ed.) Advances in written text analysis. London; New York: Routledge, 1994. p. 167-178.

SIBEON, Roger. Rethinking social theory. London; Thousand Oaks; New Delhi: Sage, 2004.

SILVERMAN, David. Doing qualitative research: a practical handbook. London; Thousand Oaks; New Delhi: Sage, 2000.

SILVERMAN, David. Interpreting qualitative data: methods for analysing talk, text and interaction. 2. ed. London; Thousand Oaks; New Delhi: Sage, 2001.

STRAUSS, Anselm; CORBIN, Juliet. Basics of qualitative research: grounded theory procedures and techniques. Newbury Park: Sage, 1998.

TAYLOR, William. Organizational culture and administrative leadership in universities. In: SERGIOVANNI, Thomas J.; CORBALLY, John E. (ed.). Leadership and organizational culture: new perspectives on administrative theory and practice. Urbana; Chicago: University of Illinois Press, 1986. p. 125-142.

TRIPODI, Zara Figueiredo; SOUSA, Sandra Zákia. A governança em rede na regulação da educação básica mineira: quem governa o quê? Educação em Revista, Belo Horizonte, v. 3, n. 0, p. 297-321, 2016. 
VALA, Jorge. A análise de conteúdo. In: SILVA, Augusto Santos; PINTO, José Madureira (org.). Metodologia das ciências sociais. Porto: Afrontamento, 1986. p. 101-128.

VAUGHAN, Diane. Criminology and the sociology of organizations. Crime, Law \& Social Change, Netherlands, v. 2, n. 37, p. 117-136, 2002.

WALLACE, Walter L. The logic of science in sociology. Chicago: Transaction, 1971.

WEBER, Max. Economy and society. Berkeley: University of California Press, 1978.

WEBER, Max. Ensaios de sociologia. Rio de Janeiro: Guanabara, 1982.

WEBER, Max. Fundamentos da sociologia. 2. ed. Porto: Rés, 1983.

WEBER, Max. Metodologia das ciências sociais. Parte 1. São Paulo: Cortez, 1992.

WELCH, Catherine; RUMYANTSEVA, Maria; HEWERDIN, Lisa Jane. using case research to reconstruct concepts: a methodology and illustration. Organizational Research Methods, London, v. 19, n. 1, p. 111-130, 2016.

Recebido em: 25.11.2019.

Revisado em: 01.07.2020.

Aprovado em: 04.08.2020.

Ivo Domingues é doutor em Sociologia - ramo Sociologia das organizações; membro do Departamento de Sociologia do Instituto de Ciências Sociais e do Centro de Estudos de Comunicação e Sociedade (CECS) da Universidade do Minho (Portugal).

Maria José Costa é mestre em Sociologia; doutoranda em Sociologia e investigadora do Centro de Estudos de Comunicação e Sociedade (CECS), do Instituto e Ciências Sociais, da Universidade do Minho (Portugal). 